\title{
Perancangan Sistem Informasi Perpustakaan di MTs Roudlotul Khuffadz Berbasis Web
}

\author{
Muhammad Soleh ${ }^{1}$, Muhammad Ihsan ${ }^{2}$, Matahari ${ }^{3}$. \\ Universitas Pendidikan Muhammadiyah Sorong \\ achmadm915@gmail.com, ihsanrockmantic01@gmail.com,mataharitarie@gmail.com
}

\begin{abstract}
Abstrak: Sistem informasi perpustakaan MTs Roudlotul Khuffadz merupakan sistem informasi yang mengolola administrasi perpustakaan. Tujuan dilakukan penelitian di MTs Roudlotul Khuffadz adalah untuk mengetahui langkah-langkah perancangan sistem informasi perpustakaan untuk membantu dan mempermudah pengelolaan kegiatan administrasi perpustakaan MTs Roudlotul Khuffadz dan mengetahui langkah-langkah pengoprasian sistem dengan menyajikan buku panduan pengoprasian. Desain penelitian perancangan sistem informasi perpustakaan menggunakan metode research and development (R\&D), dengan prosedur pengembangan menggunakan model prototyping. Hasil uji coba lapangan dengan penilain kualitas sistem mendapatkan rata-rata 3,5 dan presentase $89 \%$, navigasi mendapat rata-rata 3,6 dan presentase 90\%, kepuasan terhadap pengguna mendapatkan rata-rata 3,6 dan presentase $89 \%$, dan dampak bagi MTs Roudlotul Khuffadz mendapatkan rata-rata 3,6 dan presentase $90 \%$, kemudahan memahami buku panduan oleh responden mendapatkan nilai rata-rata 3,4 dan presentase $86 \%$ dengan kesimpulan sangat baik. Disimpulkan perancangan sistem informasi perpustakaan MTs Roudlotul Khuffadz secara keseluruhan mendapat predikat sangat baik.
\end{abstract}

Kata kunci: Informasi; Perpustakaan; Prototyping; Sistem; Web.

Abstract: MTs Roudlotul Khuffadz library information system is the information system that manages library administration. The purpose of this research at MTs Roudlotul Khuffadz is to find out the steps for designing a library information system that can help and facilitate the management of administrative activities in the MTs Roudlotul Khuffadz library and to know the steps for operating the system, presenting an operation manual. The research design of library information system design uses the research and development $(R \& D)$ development method, with the development procedure using a prototyping model. Meanwhile, the results of field trials with system quality assessment get an average of 3.5 and a percentage of $89 \%$, navigation gets an average of 3.6 and a percentage of $90 \%$, satisfaction with users gets an average of 3.6 and a percentage of $89 \%$, and the impact on MTs Roudlotul Khuffadz got an average of 3.6 and a percentage of $90 \%$, the ease of understanding the guidebook by the respondents got an average score of 3.4 and a percentage of $86 \%$ with very good conclusions. It can be concluded that the overall design of the MTs Roudlotul Khuffadz library information system received a very good predicate.

Keywords: Information; Library; Prototyping; System; Web 


\section{Pendahuluan}

Madrasah Tsanawiyah (MTs) Roudlotul Khuffadz adalah sekolah yang telah berdiri pada tahun 2011. Sekolah yang terletak di jalan Wortel, Lorong Kakatua, Kelurahan Malasom, Distrik Aimas, Kabupaten Sorong, Papua Barat ini memiliki jumlah ruang kelas sebanyak 6 ruang kelas, 1 ruang lab komputer, 1 ruang perpustakaan dan beberapa ruang lainnya sebagai ruang penujang di sekolah. Sekolah yang memiliki luas tanah $1.008 \mathrm{M}^{2}$ memiliki jumlah tenaga pengajar sebanyak 27 guru yang terbagi atas 1 guru pegawai negeri sipil (PNS) daerah, 13 guru Non PNS, 3 guru tetap yayasan (GTY) dan 10 guru tidak tetap (GTT). Selain tenaga pengajar, MTs Roudlotul khuffadz memiliki 1 orang staf tata usaha (TU) dan 4 pengurus komite sekolah. Jumlah siswa-siswi di MTs Roudlotul Khuffadz saat ini sebanyak 132 orang.

Berdasarkan hasil observasi yang dilakukan oleh peneliti, ditemukan bahwa perpustakaan di MTs Roudlotul Khuffadz masih menggunakan cara konvensional dalam mengelola administrasi perpustakaan. Administrasi di perpustakaan yang masih menggunakan pencatatan secara tulis tangan, baik data peminjaman buku, pengembalian buku, buku masuk, bahkan laporan akhir perpustakaan tiap semester yang harus diketik terpisah setelah semua data disalin dari buku induk perpustakaan. Hal ini membuat para siswa dan guru masih mencari buku satu persatu di perpustakaan, dari rak satu ke rak yang lainnya, bahkan tak jarang buku yang dicari pun ternyata tidak ditemukan, hal ini merepotkan bagi siswa, guru maupun penjaga perpustakaan. Tidak hanya siswa dan guru yang mendapat kendala dalam hal ini, melainkan penjaga perpustakaan pun mendapatkan kendala lain tentang pengelolaan data perpustakaan.

\section{Metode Penelitian}

Pada Penelitian ini, peneliti menggunakan model penelitian Research and Development (R\&D) atau Penelitian dan Pengembangan. Penelitian dan Pengembangan merupakan pendekatan penelitian untuk menghasilkan produk baru atau menyempurnakan produk yang telah ada. Produk yang dihasilkan bisa berupa Software, ataupun hardware seperti buku, modul, paket, program pembelajaran, ataupun alat bantu belajar lainnya. Sedangkan Prosedur pengembangan penelitian menggunakan model prototyping. Prototype adalah model kerja dasar dari pengembangan sebuah program (software) atau perangkat lunak. Model prototyping mengabaikan prosedur yang panjang dan memakan waktu yang lama.

Penelitian dilakukan di MTs Roudlotul Khuffadz, Sorong, Papua Barat mulai 20 April 24 Sepetember 2020. Subjek penelitian pada penelitian ini adalah siswa, guru, staf sekolah, mahasiwa dan masyarakat kabupaten Sorong.

\section{Hasil dan Pembahasan}

Hasil pengembangan sistem informasi perpustakaan MTs Roudlotiul Khuffadz menghasilkan sebuah sistem yang dapat membantu pengelola administrasi di perpustakaan sekolah. Sistem yang memiliki 4 menu utama ini seperti, Home, Data Buku, Data Anggota, dan Data Transaksi. Petunjuk penggunaan sistem informasi perpustakaan MTs Roudlotul Khuffadz disajikan dengan menggunakan buku panduan yang dapat di download pada sistem informasi perpustakaan 


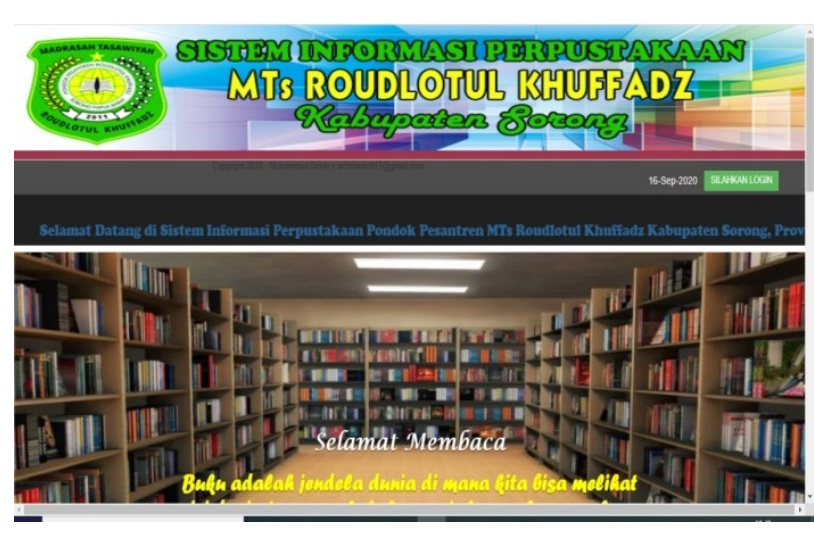

Gambar 1. Tampilan awal SI

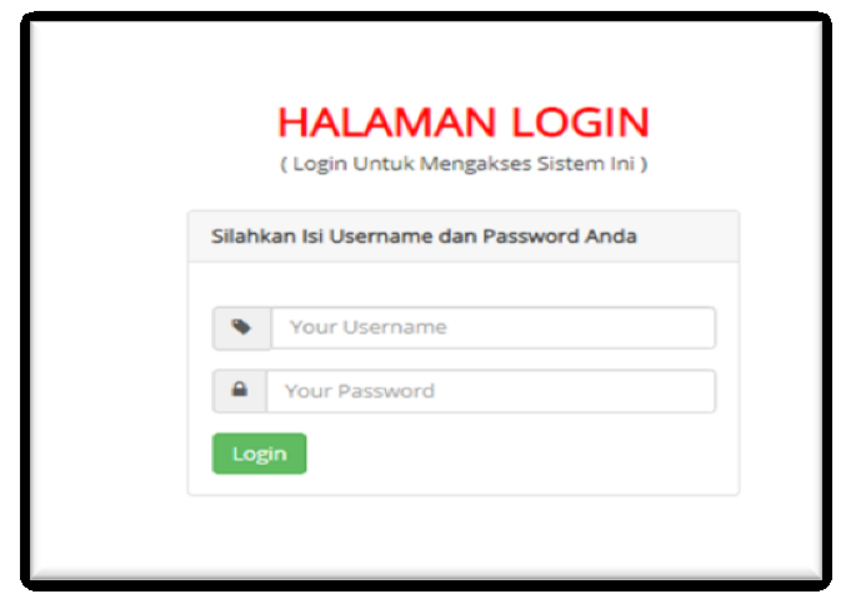

Gambar 3. Tampilan Login

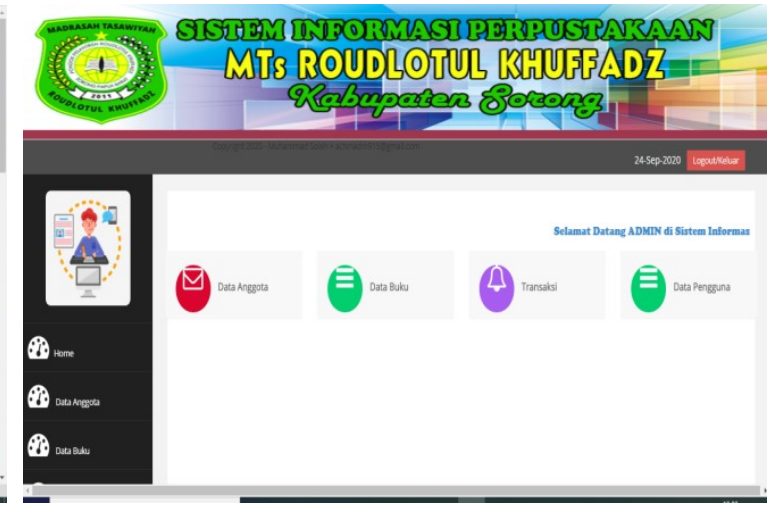

Gambar 2. Tampilan Utama Admin

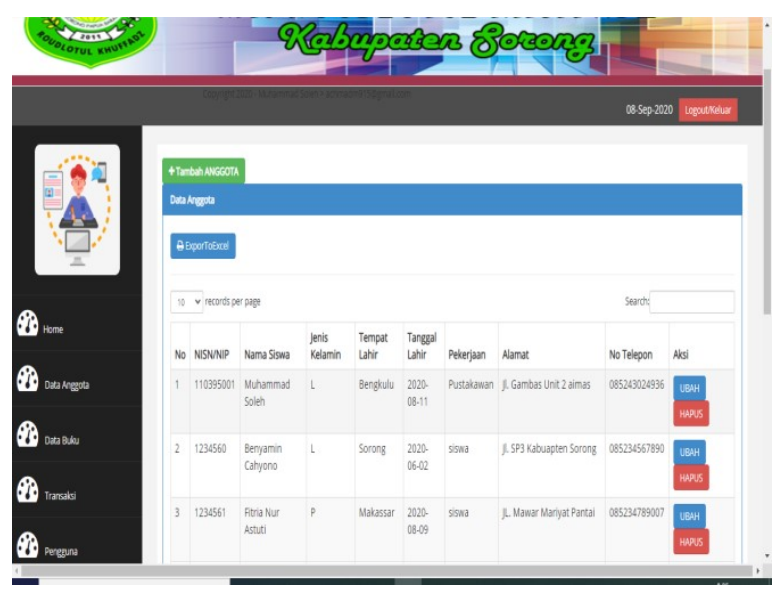

Gambar 4. Tampilan menu Anggota

Pengujian dilakukan dengan beberapa cara yaitu pengujian blackbox, pengujian validasi terhadap ahli dan pengujian lapangan.

a. Pengujian blackbox

Pengujian blackbox merupakan pengujian sistem yang dilakukan untuk menguji secara fungsional agar mengetahui kesesuain sistem sesuai dengan yang diharapkan. Berdasarkan hasil pengujian blackbox oleh validator ahli didapatkan hasil kesesuai secara keseluruhan dengan hasil yang sangat baik.

b. Hasil Pengujian Lapangan

Berdasrakan hasil uji lapngan yang dilakukan oleh meneliti melalui empat instrument yaitu (1) kualitas sistem, (2) navigasi, (3) kepuasan pengguna, dan (4) dampak bagi MTs Roudlotul Khuffadz didapatkan hasil dengan keseluruhan rata-rata kualitas sistem 3,5 dengan presentase 89\%, navigasi mendaptkan rata-rata 3,6 dengan presentase $90 \%$, kepuasan pengguna mendapatkan rata-rata 3,6 dengan presentase $89 \%$ dan dampak bagi MTs Roudlotul Khuffadz dengan rata-rata 3,6 dengan prsentasi $90 \%$ dengan kesimpulan keselurahan mendapatkan hasil sangat baik yang dapat dilihat pada Tabel 1. 
Tabel 1. Kualitas Sistem

\begin{tabular}{clccc}
\hline No & \multicolumn{1}{c}{ Kualitas sistem } & Rata-Rata & Presentase & Kesimpulan \\
\hline 1 & Mudah dipahami & 3,7 & $92 \%$ & Sangat Baik \\
2 & Mudah digunakan & 3,7 & $93 \%$ & Sangat Baik \\
3 & $\begin{array}{l}\text { Memudahkan dalam proses } \\
\text { administrasi sistem }\end{array}$ & 3,5 & $88 \%$ & Sangat Baik \\
4 & $\begin{array}{l}\text { Memudahkan dalam proses } \\
\text { transaksi }\end{array}$ & 3,6 & $89 \%$ & Sangat Baik \\
5 & $\begin{array}{l}\text { Dapat digunakan di } \\
\text { berbagai perangkat } \\
\text { (Handphone /laptop) }\end{array}$ & 3,5 & $88 \%$ & Sangat Baik \\
6 & $\begin{array}{l}\text { Memberikan informasi } \\
\text { seputar perpustakaan yang } \\
\text { relevan }\end{array}$ & 3,6 & $89 \%$ & Sangat Baik \\
7 & $\begin{array}{l}\text { Inputan/masukan sistem } \\
\text { sesuai dengan output/ } \\
\text { keluaran }\end{array}$ & 3,5 & $88 \%$ & Sangat Baik \\
Tidak terdapat kesalahan \\
(error) pada saat sistem \\
dijalankan
\end{tabular}

Diagram 1. Kualitas Sistem

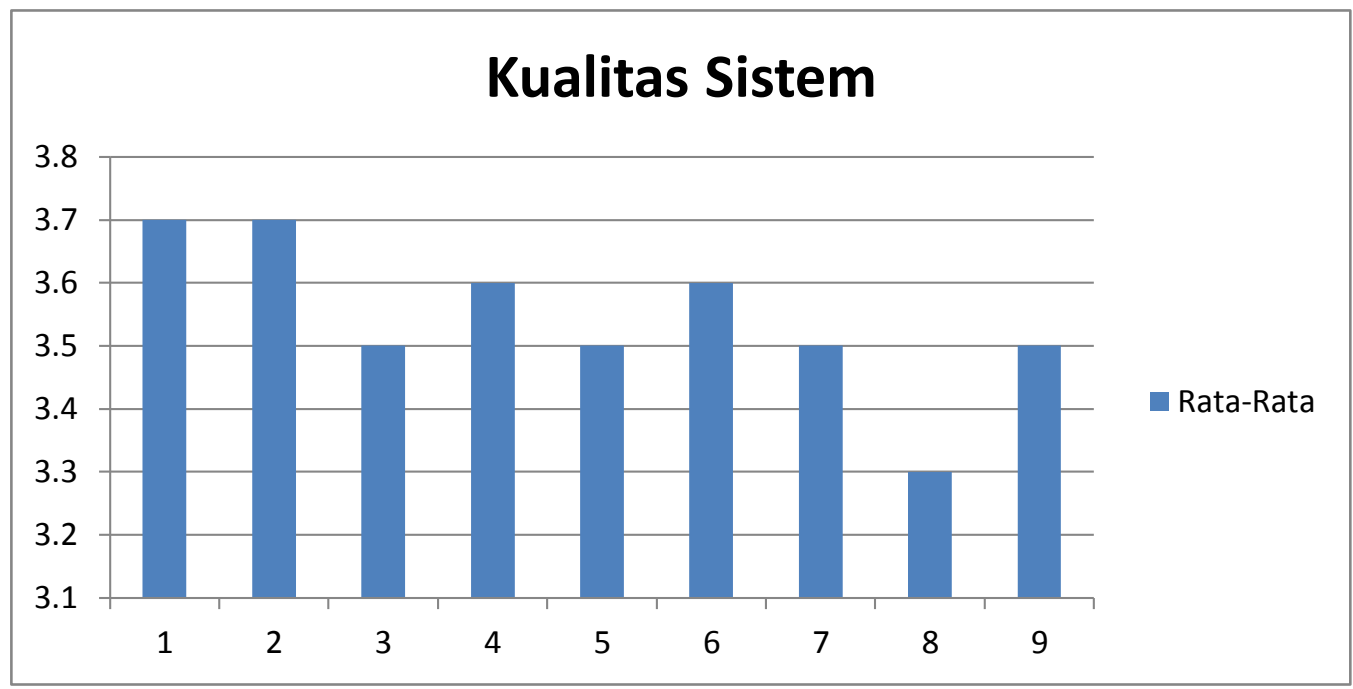


Tabel 2. Navigasi

\begin{tabular}{clccc}
\hline No & \multicolumn{1}{c}{ Navigasi } & Rata-Rata & Presentase & Kesimpulan \\
\hline 1 & Kemudahan memilih menu & 3,5 & $87 \%$ & Sangat Baik \\
2 & $\begin{array}{l}\text { Kemudahan penggunaan } \\
\text { menu }\end{array}$ & 3,8 & $94 \%$ & Sangat Baik \\
3 & $\begin{array}{l}\text { Ada peringatan jika } \\
\text { melakukan kesalahan login } \\
\text { atau input data }\end{array}$ & 3,5 & $88 \%$ & Sangat Baik \\
\hline \multicolumn{2}{c}{ Keseluruhan } & $\mathbf{3 , 6}$ & $\mathbf{9 0 \%}$ & Sangat Baik \\
\hline
\end{tabular}

Diagram 2. Navigasi

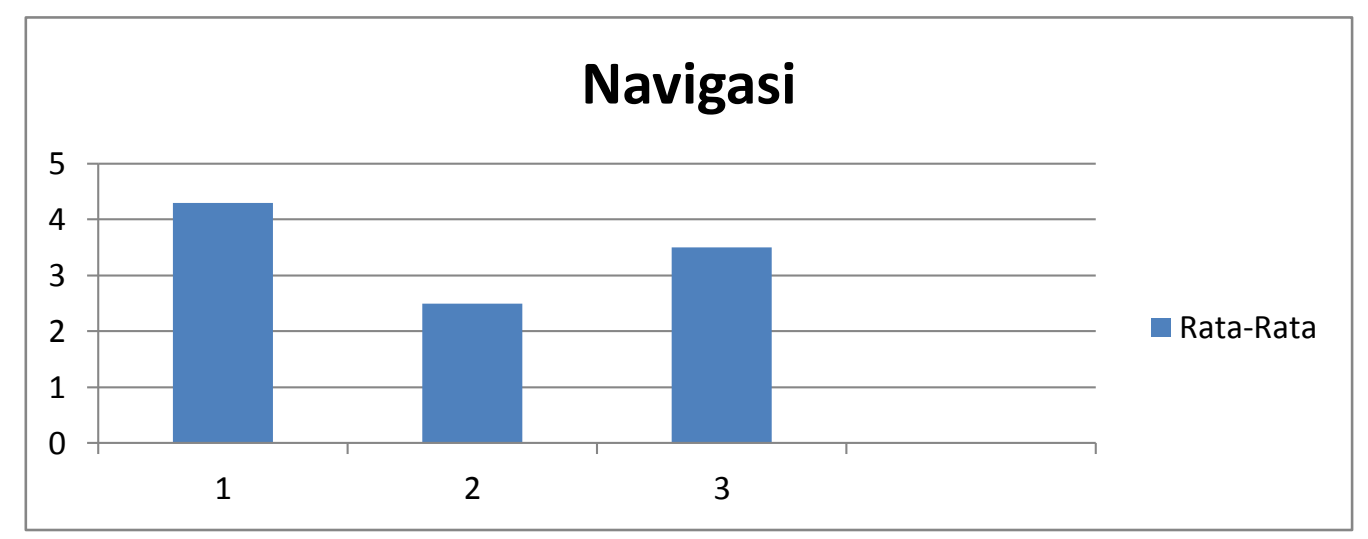

Tabel 3. Kepuasan Pengguna

\begin{tabular}{ccccc}
\hline No & Kepuasan Pengguna & Rata-Rata & Presentase & Kesimpulan \\
\hline 1 & $\begin{array}{l}\text { Puas terhadap hasil sistem } \\
\text { yang telah dikembangkan. }\end{array}$ & 3,7 & $92 \%$ & Sangat Baik \\
2 & $\begin{array}{l}\text { Buku petunjuk penggunaan } \\
\text { manarik dan mudah } \\
\text { dipahami. }\end{array}$ & 3,4 & $86 \%$ & Sangat Baik \\
\hline Keseluruhan & $\mathbf{3 , 6}$ & $\mathbf{8 9 \%}$ & Sangat Baik \\
\hline
\end{tabular}

Diagram 3. Kepuasan Pengguna

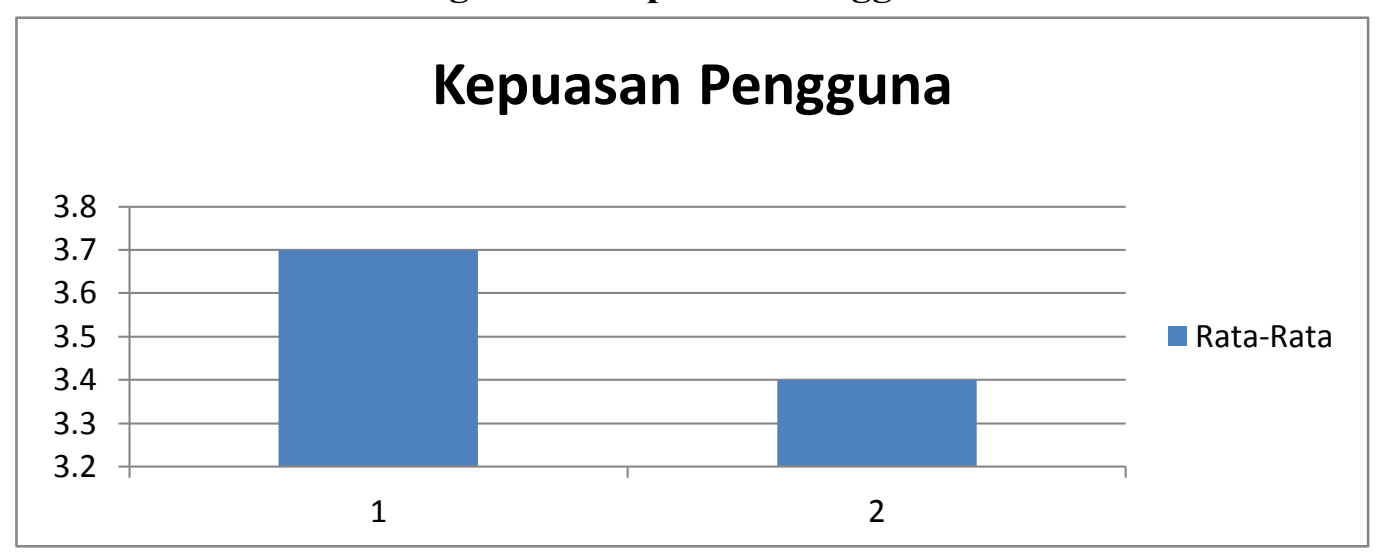


Tabel 4. Dampak Bagi MTs Roudlotul Khuffadz

\begin{tabular}{ccccc}
\hline No & Kepuasan Pengguna & Rata-Rata & Presentase & Kesimpulan \\
\hline 1 & $\begin{array}{l}\text { Menghemat tenaga, waktu } \\
\text { dan biaya }\end{array}$ & 3,5 & $88 \%$ & Sangat Baik \\
2 & 3,7 & $92 \%$ & Sangat Baik \\
$\begin{array}{l}\text { Membantu proses } \\
\text { pelaksanaan adminitrasi } \\
\text { menjadi lebih efektif. }\end{array}$ & & $\mathbf{3 , 6}$ & $\mathbf{9 0 \%}$ & Sangat Baik \\
\hline \multicolumn{1}{c}{ Keseluruhan } & & & \\
\hline
\end{tabular}

Diagram 4. Dampak Bagi MTs Roudlotul Khuffadz

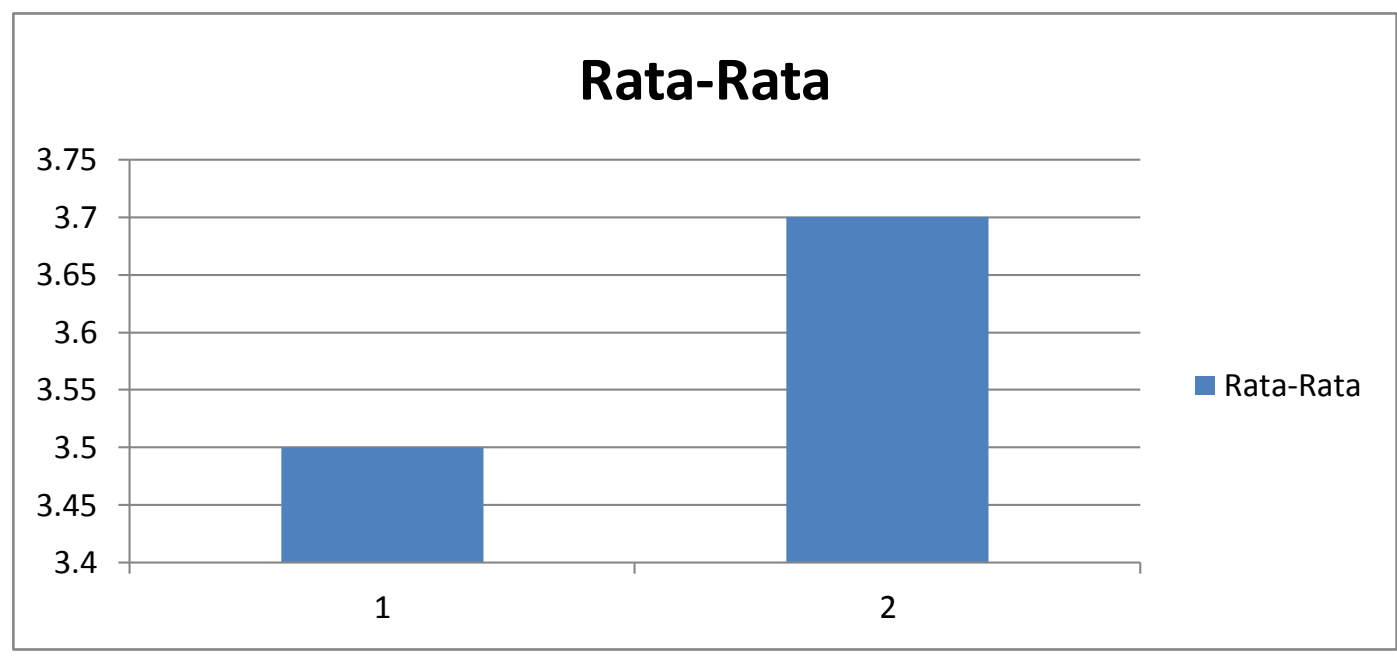

\section{Kesimpulan dan Saran}

Perancangan Sistem Infomasi Perpustakaan di MTs Roudlotul Khuffadz Berbasis Web berhasil dibagun dan digunakan. Sistem ini mampu memberikan informasi terkait dengan data perpustakaan di MTs Roudlotul Khuffadz dan memudahkan administrasi perpustakaan di sekolah. Terdapat 3 aspek yang dinilai oleh validator (ahli) untuk menilai kevalidan sistem informasi perpustakaan MTs Roudlotul Khuffadz. Aspek validasi ahli diantaranya aspek pemograman mendapatkan rata-rata 3,6 dan presentase 90\%, aspek tampilan mendapatkan rata-rata 3,7 dan presentase 92\%, dan aspek pengguna mendapatkan rata-rata 3,8 dan presentase 94\%. Sedangkan, hasil uji coba lapangan dengan penilain kualitas sistem mendapatkan rata-rata 3,5 dan presentase $89 \%$, navigasi mendapat rata-rata 3,6 dan presentase $90 \%$, kepuasan terhadap pengguna mendapatkan rata-rata 3,6 dan presentase $89 \%$, dan dampak bagi MTs Roudlotul Khuffadz mendapatkan rata-rata 3,6 dan presentase 90\% dengan mendapatkan kesimpulan keseluruhan sangat baik. Sistem informasi perpustakaan MTs Roudlotul Khuffadz dapat dioperasikan oleh setiap orang dengan adanya buku panduan pengoprasian sistem. Berdasarkan hasil uji coba lapangan, kemudahan memahami buku panduan oleh responden mendapatkan nilai rata-rata 3,4 dan presentase $86 \%$ dengan kesimpulan sangat baik. 


\section{Daftar Pustaka}

Abdulloh, R. (2018). 7 In 1 Pemograman Web Untuk Pemula. PT Alex Mediakoputido.

Anggraeni, E. Y. (2017). Pengantar Sistem Informasi (E. Risanto (ed.)). CV. Andi Offset.

Azis, S. (2018). Menguasai Php Dan Mysql (P. Dianing (ed.)). Jakarta: kuncikom. nterprise, J. (2014). Mysql Untuk Pemula. PT Alex Mediakoputido.

Enterprise, J. (2017). PHP Komplit. PT Alex Media Komputindo.

Krisianto, A. (2014). Internet Untuk pemula. PT Alex Media Komputindo.

Kurniawan, B. (2008). Desain Web Praktis Dengan CSS (W. whindy Yoevesstian (ed.)). PT Alex Media koputido

Rerung, R. R. (2018). Pemograman Web Dasar. CV Budi Utama.

Setiawan, D. (2018). Buku Sakti Pemograman WEB, HTML, PHP, MYSQL, \& Javasript (N. Lestari (ed.); Sony Adams). START UP.

Ruswana,U.(2019). Teknik Penulisan Tugas Akhir dan Skripsi Pemograman. PT. Alex Media Komputindo.

Ariwibowo, D.,Riyanto, V., Rakhmah, S. (2017) . Sistem Informasi Perpustakaan Berbasis Web Pada SMK Negeri 2 Kota Bekasi. Jurnal Indikator, 1, 41-43.

Rohayati., Irwandi, A. (2016). Perancangan dan Implementasi Sistem Informasi Inventaris Laboratorium. Jurnal Intekna, 16, 15-16.

Rahadian, G., Rohanda., Anwar R. (2014). Peranan Perpustakaan Sekolah Dalam MeningkatkanBudaya Gemar Membaca. Jurnal Kajian Informasi \& Perpustakaan, 2, 28-32.

Ariansyah., Fajriyah., Febby Satryadi Prasetyo. (2017). Rancang Bangun Sistem Informasi Pendataan Alumni Pada Stie Prabumulih Berbasis Website Dengan Menggunakan Bootstrap, Jurnal Mantik Penusa, Vol. 1, No 2.

Andi Christian., Sebri Hesinto., Agustina. (2018). Rancang Bangun Website Sekolah Dengan Menggunakan Framework Bootstrap (Studi Kasus SMP Negeri 6 Prabumulih ), Jurnal SISFOKOM, Vol 07, No 01,

Dian Novianto (2016). Implementasi Sistem Informasi Pegawai (Simpeg) Berbasis Web Menggunakanframework Codeigniter Dan Bootstrap. Jurnal Ilmiah Informatika Global Vol 7, No 1.

Aliyah, I., Matahari, M., \& Firman, F. (2020). Perancangan Sistem Informasi Nilai Mahasiswa Berbasis Web pada Prodi PTI FKIP UNIMUDA Sorong. JURNAL PETISI (Pendidikan Teknologi Informasi), 1(1), 1-11.

Salam, I., Ihsan, M., \& Matahari, M. (2020). Perancangan Sistem Informasi Penerimaan Mahasiswa Baru Berbasis Web di FKIP UNIMUDA Sorong. JURNAL PETISI (Pendidikan Teknologi Informasi), 1(1), 12-25. 